\title{
Pregnancy Intendedness by Maternal Disability Status and Type in the United States
}

By Willi Horner-Johnson, Mekhala Dissanayake, Justine P. Wu, Aaron B. Caughey and Blair G. Darney

CONTEXT: Societal views about sexuality and parenting among people with disabilities may limit these individuals' access to sex education and the full range of reproductive health services, and put them at increased risk for unintended pregnancies. To date, however, no national population-based studies have examined pregnancy intendedness among U.S. women with disabilities.

METHODS: Cross-sectional analyses of data from the 2011-2013 and 2013-2015 waves of National Survey of Family Growth were conducted; the sample included 5,861 pregnancies reported by 3,089 women. The proportion of pregnancies described as unintended was calculated for women with any type of disability, women with each of five types of disabilities and women with no disabilities. Multivariate logistic regression analyses were conducted to examine

This is the author manuscript accepted for publication and has undergone full peer review but has not been through the copyediting, typesetting, pagination and proofreading process, which may lead to differences between this version and the Version of Record. Please cite this article as doi: $10.1363 /$ psrh.12130

This article is protected by copyright. All rights reserved. 
Horner-Johnson—LM, PSRH 52:1—3,572 text, 247 abstract

the relationship of disability status and type with pregnancy intendedness while adjusting for covariates.

RESULTS: A higher proportion of pregnancies were unintended among women with disabilities than among women without disabilities (53\% vs. 36\%). Women with independent living disability had the highest proportion of unintended pregnancies (62\%). In regression analyses, the odds that a pregnancy was unintended were greater among women with any type of disability than among women without disabilities (odds ratio, 1.4), and were also elevated among women with hearing disability, cognitive disability or independent living disability (1.5-1.9).

CONCLUSIONS: Further research is needed to understand differences in unintended pregnancy by type and extent of disability. People with disabilities should be fully included in sex education, and their routine care should incorporate discussion of reproductive planning. Perspectives on Sexual and Reproductive Health, 2020, 52(1):TK, doi:TK

Pregnancy intentions of women with disabilities have only recently 
been considered in the literature. Two population-based studies, published in 2014 and 2017, found that women with disabilities were as likely to want a baby as women without disabilities., ${ }^{1,2}$ However, women with disabilities were less likely to report actual intentions to have a baby in the future, and were less certain about their childbearing intentions, than women without disabilities..$^{1,2}$ Some of the uncertainty expressed by such women may be related to the long history of discrimination experienced by people with disabilities regarding their rights to have consensual sex and become parents.34 Even today, persistent perceptions that people with disabilities cannot or should not have children remain. . $^{3-6}$

Societal views about sexuality and reproduction among people with disabilities may limit these individuals' access to sex education and to the full range of reproductive health services. Compared with women who do not have disabilities, women with disabilities are less knowledgeable about contraception, ${ }^{7-9}$ less likely to receive family planning services ${ }^{10}$ and less likely to use long-acting reversible contraceptives (IUDs or the implant) ${ }^{11}$ and oral contraceptive pills. $^{12}$ These findings suggest that women with disabilities may be at increased risk for unintended pregnancies. Analyses of two different national data sets found that after 
adjustment for social and demographic characteristics, women with disabilities were as likely to get pregnant as women without disabilities. ${ }^{13,14}$ However, in those data sets, no information was available on whether the pregnancies were intended or unintended.

Pregnancy intentions are dynamic and nonbinary, which presents ongoing measurement challenges for researchers.15,16 For the purposes of this article, and consistent with epidemiological conventions, ${ }^{17-19}$ we use the term "unintended" to refer to pregnancies that were not wanted at all or that were wanted later than the time at which they occurred. In the general population, women with unintended pregnancies are less likely to receive timely prenatal care and engage in healthy behaviors during pregnancy, and are more likely to have preeclampsia, preterm birth and lowbirth-weight infants, than women with intended pregnancies. ${ }^{20-23}$ Moreover, unintended pregnancies have substantial effects on women's physical and mental health during and after pregnancy, including worsening of preexisting conditions. ${ }^{24}$ Thus, unintended pregnancies could be especially challenging for women with disabilities, many of whom already have complex health care needs. ${ }^{25}$ Women with disabilities are at increased risk for pregnancy complications, postpartum depression, perinatal hospitalization and 
other adverse outcomes, ${ }^{26}$ all of which could be exacerbated when pregnancies are unintended. It is therefore important to understand the intendedness of pregnancies among women with disabilities to inform efforts to optimize the timing of their pregnancies and to maximize the health and well-being of these women and their infants.

One previous study using data from a single state found that women with disabilities were significantly less likely to describe their pregnancies as intended than those without disabilities. ${ }^{27}$ However, no national population-based studies have examined pregnancy intendedness among U.S. women with disabilities. Further, women with different types of disabilities (e.g., hearing, vision, cognitive, physical) may not encounter the same barriers to obtaining reproductive health care and information, and thus may be at differential risk for unintended pregnancy; yet, no studies have examined whether and how the proportion of pregnancies that are unintended varies by disability type. To address these gaps, we examined associations between the presence and type of disability and pregnancy intention. We hypothesized that a higher proportion of pregnancies among women with disabilities than among women without disabilities would be unintended. 


\section{METHODS}

\section{Data}

We conducted cross-sectional analyses of data from the 2011-2013 and 2013-2015 waves of the National Survey of Family Growth (NSFG). The NSFG is designed and administered by the National Center for Health Statistics at the Centers for Disease Control and Prevention to obtain national estimates of behaviors and outcomes related to family life, including marriage, sexual activity, contraceptive use and pregnancy. ${ }^{28}$ Interviews are administered in person using a combination of computer-assisted personal interviewing and audio-computer assisted self-interviewing. The survey utilizes a continuous sampling design over a two-year period to provide nationally representative samples of women and men aged 15-44 who reside in civilian households. Survey procedures include oversampling of teenagers and minorities to obtain population-based data for these groups. ${ }^{29}$ The weighted response rate for women was 73\% in 2011-2013 and 71\% in 2013-2015. ${ }^{29}$

The NSFG provides data from women in two files. The female respondent file includes the social and demographic characteristics of the woman (including information on disability status and type) 
at the time of interview, along with information about her sexual and contraceptive history. A separate pregnancy file contains retrospective data about each pregnancy the woman reported. We merged data from the pregnancy files with those from the female respondent files to create a single data file, thus linking a woman's disability status with each individual pregnancy. Our analyses included all pregnancies that occurred within the five years prior to the interview, whether the pregnancy resulted in a live birth or not; a total of 5,865 pregnancies were reported as occurring during this time period. Disability data was unavailable for only four pregnancies (reported by four women); thus, our final analytic sample included 5,861 pregnancies reported by 3,089 women. Because these were deidentified publicly available data, institutional review board approval was not required.

\section{Dependent Variable}

Our dependent variable was the proportion of pregnancies (out of all pregnancies reported in the last five years) described as unintended. In accordance with well-established conventions, ${ }^{17-19}$ we classified pregnancies that were unwanted or mistimed (occurred too soon but were not unwanted) as unintended, and 
categorized all other pregnancies as intended. The latter category included pregnancies described as occurring at the right time (the vast majority of pregnancies in this category) or later than desired, and small numbers of pregnancies for which women gave "didn't care, indifferent" and "don't know, not sure" responses. Recognizing that some women acquire disabilities after entering their reproductive years, we restricted our analyses to pregnancies in the past five years to reduce the likelihood that reported pregnancies had occurred prior to disability onset.

\section{Primary Independent Variables}

Our independent variables were women's characteristics. In our descriptive analyses, these are reported with the number of women (rather than the number of pregnancies) as the denominator. We categorized disability status and type on the basis of responses to six questions on the NSFG that have been used by the U.S. Census Bureau since 2008 and were adopted in 2011 by the Department of Health and Human Services as the minimum standard for disability data collection in population-based health surveys. ${ }^{30}$ The questions were "Do you have serious difficulty hearing?" (hearing disability);

“Do you have serious difficulty seeing, even when wearing glasses 
Horner-Johnson—LM, PSRH 52:1—3,572 text, 247 abstract

or contact lenses?” (vision disability); “Because of a physical, mental or emotional condition, do you have serious difficulty concentrating, remembering or making decisions?" (cognitive disability); “Do you have serious difficulty walking or climbing stairs?" (mobility disability); "Do you have difficulty dressing or bathing?" (self-care disability); and "Because of a physical, mental or emotional condition, do you have difficulty doing errands alone, such as visiting a doctor's office or shopping?" (independent living disability).

We created a dichotomous variable indicating whether a woman answered yes to any of the disability questions. We also created separate variables for each question to compare women with each disability type and those with no disabilities. The number of women with self-care disability was small (1\% of the sample), and $80 \%$ of these women also had mobility disability (a greater degree of overlap than we found between any other two disability variables). Therefore, we combined self-care disability and mobility disability to create a "physical disability" variable. Our variables for individual disability types were not mutually exclusive; if a woman had more than one type of disability, she was included in each of the applicable disability groups. 


\section{Covariates}

In preliminary analyses, we identified covariates associated with both disability and pregnancy intendedness and adjusted for them in multivariate regression analyses. Covariates included age (categorized as 15-24, 25-34, 35-44), race or ethnicity (white, black, Hispanic and other), partner status at the time of conception (married/cohabitating vs. single/divorced/other), education (an associate's degree or higher vs. no degree), income as a percentage of the federal poverty level $(<100 \%, 100-249 \%, \geq 250 \%)$ and parity (nulliparous vs. multiparous). With the exception of partner status at the time of conception (which was reported separately for each pregnancy), covariates were reported once by women at the time of the interview. We considered insurance (private, public, uninsured) as a possible covariate; however, it was closely associated with income, raising concerns about collinearity. Of the two variables, income was more strongly associated with unintended pregnancy; thus, we selected it for inclusion in the multivariable models.

\section{Analyses}

We used chi-square tests to compare women in each disability group 
with women without disabilities for each of our covariates. We conducted bivariate analyses with chi-square tests to assess associations of disability status and type with the intendedness of pregnancy for pregnancies within the past five years. In sensitivity analyses, we assessed the associations between disability status and pregnancy intendedness using more restrictive time frames (four years, three years, two years and one year); because the prevalence of unintended pregnancy by disability status was consistent regardless of the time frame used (see Sensitivity Analyses Appendix-Supporting Information), we used the five-year time frame for our remaining analyses. In addition to the prevalence of unintended pregnancies overall, we calculated the proportions of pregnancies that were mistimed versus unwanted, by disability status and type, and used chi-square tests to identify differences between women with and without disabilities.

Next, we conducted multivariate logistic regression analyses to examine the relationship of overall disability and each of the five disability types with pregnancy intendedness, while controlling for the covariates. Because the disability categories were not mutually exclusive, we ran separate regression models for each disability type; women with no disabilities were the reference group in each model. 
We used Archer-Lemeshow goodness-of-fit tests to assess model fit; this test is similar to the Hosmer-Lemeshow goodness-of-fit test but is designed to take into account survey sampling weights and design. ${ }^{31}$ A significant F-adjusted statistic would indicate that the fitted model diverged substantially from the observed data. ${ }^{31}$ For each of our models, the F-adjusted statistic was small and the $\mathrm{p}$ value was large, raising no concerns about model fit (see Regression Analyses Appendix-Supporting Information). Lastly, because predicted probabilities are easier to interpret than odds ratios, ${ }^{32}$ we estimated the multivariable probability of unintended pregnancy for each disability group, while holding all other covariates constant.

All analyses were conducted with Stata version 14, using the survey functions to account for the NSFG's complex sampling design. We applied the pooled 2011-2015 weights provided by the National Center for Health Statistics to make the sample representative of the U.S. population, and used the provided cluster variables to account for clustering of pregnancies by woman.

\section{RESULTS}

Sixteen percent of women reported having a disability (Table 1). Compared with women without disabilities, women with 
Horner-Johnson—LM, PSRH 52:1—3,572 text, 247 abstract

disabilities were less likely to be married or cohabiting ( $60 \%$ vs. $77 \%$ )

or have a college degree (19\% vs. $42 \%)$, and were more likely to be living below the federal poverty line ( $47 \%$ vs. $30 \%)$. Overall, women with disabilities were more likely to be nulliparous than their counterparts without disabilities (13\% vs. 9\%); however, women with physical disabilities or independent living disabilities did not differ from those without disabilities in this regard. The proportion of women who were black was twice as high among those with vision disability than among those without disabilities (28\% vs. $14 \%)$, and the proportion who were Hispanic among those with this disability was slightly higher (25\% vs. $23 \%)$.

Of all of the pregnancies in our sample, $39 \%$ were unintended, and $17 \%$ occurred to women with disabilities (not shown). Compared with pregnancies among women without disabilities, a significantly higher proportion of pregnancies occurring among women with disabilities were unintended $(53 \%$ vs. $36 \%$-Figure 1$)$. The proportion of pregnancies that were unintended was significantly higher among women in each disability subgroup than that among women without disabilities, and ranged from $47 \%$ among women with physical disabilities to $62 \%$ among women with independent living disability. In analyses restricted to unintended pregnancies, 
Horner-Johnson—LM, PSRH 52:1—3,572 text, 247 abstract

we found no differences by disability status or type in the proportions of unintended pregnancies that were mistimed versus unwanted.

The odds of unintendedness varied by disability type (Figure 2). In regression analyses that adjusted for covariates, pregnancies among women with any type of disability were more likely to be unintended than pregnancies among women without disabilities (odds ratio, 1.4). We found significantly higher odds of unintendedness for pregnancies among women with hearing disability, cognitive disability and independent living disability than among women without disabilities (1.5-1.9). The odds that a pregnancy was unintended did not differ between women with vision or physical disabilities and those without disabilities. The full multivariate results are presented in the Regression Analyses Appendix.

The predicted probabilities indicated the estimated proportions of pregnancies that would be unintended among women with and without disabilities, in a population with characteristics similar to our sample, with all covariates held at the mean (not shown). In this scenario, the estimated proportion of pregnancies that would be unintended was 36\% (95\% confidence interval [CI], 33-39\%) among 
Horner-Johnson—LM, PSRH 52:1—3,572 text, 247 abstract

women without disabilities, but significantly higher-44\% (95\% CI, 40-48\%) - among women with disabilities. The proportions would also be elevated among some subgroups of women with disabilities, including those with hearing disability (46\%; 95\% CI, 37-56\%), cognitive disability (45\%; 95\% CI, 40-50\%) and independent living disability (49\%; 95\% CI, 39-59\%). The predicted probabilities for women with vision disability (34\%; 95\% CI, 27-41\%) and physical disability (39\%; 95\% CI, 29-48\%) were similar to those for women without disabilities.

\section{DISCUSSION}

This study is the first to examine unintended pregnancy in relation to disability in a nationwide population-based sample of U.S. women. We found that pregnancies among women with disabilities were more likely to be unintended than those among women without disabilities. Even after adjustment for covariates, the odds that a pregnancy was unintended were higher among women with disabilities overall, and among those with three types of disabilities (hearing, cognitive and independent living), than among women without disabilities.

Our findings regarding unintended pregnancy among women 
with difficulty hearing were consistent with research on sexual risk behaviors in the deaf population. One such study found that deaf adults were more likely than adults in the general population to have had multiple sex partners in the past 12 months. ${ }^{33}$ Although that study also reported that deaf adults were more likely than adults in the general population to have used condoms at last intercourse, only $28 \%$ did so (and no data were available on use of other contraceptive methods). ${ }^{33}$ Other studies have found that deaf college students were less likely to consistently use condoms than students in the general college population, ${ }^{34}$ and more likely to rely on withdrawal to prevent pregnancy. ${ }^{9}$ Individuals with difficulty hearing-particularly deaf users of American Sign Language (ASL)-often have reduced health literacy, experience poor communication with health professionals and have limited access to sexual health information in ASL. ${ }^{33,35-37}$ These factors may serve as barriers to obtaining knowledge about effective contraceptive methods, and may place women with hearing disability at increased risk for unintended pregnancy.

Like women with hearing disability, women with vision disability also may encounter barriers to accessing information about pregnancy and contraception. ${ }^{6}$ However, in our analyses, the 
magnitude of the association between disability and unintended pregnancy was not as great for women with vision disability as it was for women in most other disability groups. Although people with limited vision may need information in nonwritten formats, they may experience fewer challenges obtaining and understanding relevant information than individuals who require ASL interpreters or those who have cognitive disabilities. It is noteworthy that the vision disability group had the highest proportions of women who were black or Hispanic; unintended pregnancy is more common among both of these racial and ethnic groups than among white women. ${ }^{17,19}$ When we adjusted for race or ethnicity and other social and demographic characteristics, the odds that a pregnancy was unintended were no different for women with vision disability than for those without disability. Similarly, although barriers to reproductive services have been noted for women with physical disabilities, ${ }^{38,39}$ the odds of unintendedness did not differ between women with physical disabilities and those without disabilities after adjustment for covariates.

Women with cognitive disability were disproportionately likely to have social and demographic characteristics associated with unintended pregnancy. However, even when those covariates were 
adjusted for, the odds of a pregnancy being unintended were significantly elevated among this group of women. This finding must be considered within the context of the United States' history of reproductive coercion (including forced sterilization) of women with cognitive disabilities. ${ }^{3}$ Even today, the rights of women with cognitive disabilities to decide if and when to become pregnant and to parent are not widely valued, which contributes to decreased access to and support for sexual and reproductive health education and services in this population. ${ }^{3,40,41}$ Prior research has suggested that reproductive knowledge may be particularly low among women with cognitive disabilities. ${ }^{8,42}$ In some cases, women with cognitive disabilities may not receive any information about contraception or even be aware that they can get pregnant until a pregnancy occurs. ${ }^{43,44}$ These factors may help explain the relatively high proportion of unintended pregnancies among women with cognitive disability. To support optimal timing of pregnancies, the reproductive potential of women with cognitive disabilities should be acknowledged, appropriate sex education should be provided and reproductive planning conversations should be incorporated into routine care.

The highest proportion and odds of unintendedness were found 
for pregnancies to women with independent living disability. Some such women may struggle with the higher-level executive and planning functions that are important for parenting. They may need significant support in raising children, yet fewer than half said they were married or had a cohabiting partner. Further, more than half were living in poverty. Financial and community resources to provide a supportive environment for parenting may be especially needed for women with independent living disability. Moreover, targeted efforts are needed to help women with independent living difficulties engage in proactive pregnancy planning so that pregnancies are optimally timed.

It is important to emphasize that the concept of "unintendedness" may be qualitatively different for women with and without disabilities. As noted earlier, previous studies have found that women with disabilities were as likely to desire a future pregnancy as those without disabilities, but less likely to be certain of their intentions to have a child. ${ }^{1,2}$ That discrepancy may reflect uncertainty among women with disabilities about their ability to get pregnant or their opportunities to do so. Such uncertainty may, in turn, be influenced by the messages women with disabilities receive throughout their lives about sexuality and parenthood in the context 
Horner-Johnson—LM, PSRH 52:1—3,572 text, 247 abstract

of disability. More research is needed on the factors women with disabilities consider when contemplating future pregnancies (including implicit and explicit constraints on their ability to fulfill their reproductive desires), and when describing the intendedness of current or prior pregnancies.

\section{Limitations and Strengths}

Our study is limited by the nature of the data source. NSFG respondents must be able to listen to or read questions without assistance and respond to survey questions independently;29 thus, some women with disabilities may not have been included. Further, the survey did not collect information on the duration of the disability or the timing of disability onset, so we were not able to determine the woman's disability status in relation to when a pregnancy occurred. Although some disabilities are lifelong, others are acquired later in life and can be temporary, episodic or permanent. ${ }^{45,46}$ We attempted to mitigate the impact of uncertainty about the timing of disability by restricting our analyses to pregnancies that occurred in the preceding five years. Moreover, we conducted sensitivity analyses with shorter time frames and found consistent results. However, it is still possible that disability status 
Horner-Johnson—LM, PSRH 52:1—3,572 text, 247 abstract

for some of the included pregnancies was miscategorized, i.e., some women who had a disability when they completed the NSFG may not have had the disability at the time of their pregnancy. Such miscategorizations would bias our results toward the null. Important strengths of our study include the population-based nature of the sample, and our pooling of two waves of data, which provided a sufficiently large sample to enable us to analyze intendedness in relation to different types of disability.

\section{Conclusions}

We found that women with disabilities had elevated proportions and odds of unintended pregnancy. Research in the general population indicates that outcomes for both women and infants are likely to be better when pregnancies are intended.20-23 That may be especially true for women with disabilities, who may have complex medical situations and additional support needs. Thus, the greater prevalence of unintended pregnancy we found among women with disabilities is concerning. Further research is needed to better understand the reasons for unintended pregnancy among women with different types of disabilities. It is also important to ensure that sex education fully includes individuals with disabilities; this would 
Horner-Johnson—LM, PSRH 52:1—3,572 text, 247 abstract

require appropriate accommodations (e.g., sign language

interpretation, simple language and clear pictures, tactile models) to

facilitate learning. Routine care for people with disabilities should

incorporate discussion of reproductive planning. In addition,

disability-specific decision support tools may be helpful for

engaging women with disabilities in pregnancy planning. 
Horner-Johnson-LM, PSRH 52:1—3,572 text, 247 abstract

\section{REFERENCES}

1. Bloom TL et al., Fertility desires and intentions among U.S. women by disability status: findings from the 2011-2013 National Survey of Family Growth, Maternal and Child Health Journal, 2017, 21(8):1606-1615, http://dx.doi.org/10.1007/s10995-016-22503.

2. Shandra CL, Hogan DP and Short SE, Planning for motherhood: fertility attitudes, desires and intentions among women with disabilities, Perspectives on Sexual and Reproductive Health, 2014, 46(4):203-210, http://dx.doi.org/10.1363/46e2514.

3. Glidden L, Removing reproductive, sexual and rearing rights of women with intellectual disability: congratulated, condoned and condemned, in: Lutzker JR, Guastaferro K and Benka-Coker ML, eds., Maltreatment of People with Intellectual and Developmental Disabilities, Washington, DC: American Association on Intellectual and Developmental Disabilities, 2016, pp. 163-186.

4. National Council on Disability, Rocking the Cradle: Ensuring the Rights of Parents with $\begin{array}{lll}\text { Disabilities Their } \quad \text { Children, } & \text { 2012, }\end{array}$ https://www.ncd.gov/sites/default/files/Documents/NCD_Parenting_508_0.pdf.

5. Iezzoni LI et al., "How did that happen?" Public responses to women with mobility disability during pregnancy, Disability and Health Journal, 2015, 8(3):380-387, http://dx.doi.org/10.1016/j.dhjo.2015.02.002.

6. Krupa $C$ and Esmail S, Sexual health education for children with visual impairments: talking about sex is not enough, Journal of Visual Impairment $\mathcal{E}$ Blindness, 2010, 104(6):327-337, http://dx.doi.org/10.1177/0145482X1010400603.

7. Cheng M and Udry J, How much do mentally disabled adolescents know about sex and birth control? Adolescent \& Family Health, 2003, 3(1):28-38. 
Horner-Johnson—LM, PSRH 52:1—3,572 text, 247 abstract

8. Pownall J, Wilson S and Jahoda A, Health knowledge and the impact of social exclusion on young people with intellectual disabilities, Journal of Applied Research in Intellectual Disabilities, 2017, http://dx.doi.org/10.1111/ jar.12331.

9. Sawyer R and Desmond S, A comparison of sexual knowledge, behavior and sources of health information between deaf and hearing university students, Journal of Health Education, 1996, 27(3):144-152, http://dx.doi.org/10.1080/10556699.1996. 10603187.

10. Mosher $\mathrm{W}$ et al., Disparities in receipt of family planning services by disability status: new estimates from the National Survey of Family Growth, Disability and Health Journal, 2017, 10(3):394-399, http://dx.doi.org/10.1016/j.dhjo.2017.03.014.

11. Wu JP et al., Use of reversible contraceptive methods among U.S. women with physical or sensory disabilities, Perspectives on Sexual and Reproductive Health, 2017, 49(3):141-147, http://dx.doi.org/10.1363/psrh.12031.

12. Mosher $\mathrm{W}$ et al., Contraceptive use by disability status: new national estimates from the National Survey of Family Growth, Contraception, 2018, 97(6):552-558, http://dx.doi.org/10.1016/j.contraception.2018.03.031.

13. Iezzoni LI et al., Prevalence of current pregnancy among US women with and without chronic physical disabilities, Medical Care, 2013, 51(6):555-562, http://dx.doi.org/10.1097/MLR.0b013e318290218d.

14. Horner-Johnson W et al., Pregnancy among US women: differences by presence, type and complexity of disability, American Journal of Obstetrics \& Gynecology, 2016, 214(4):529.e1-529.e9, http://dx.doi.org/10.1016/j.ajog. 2015.10.929.

15. Santelli JS et al., Toward a multidimensional measure of pregnancy intentions: evidence from the United States, Studies in Family Planning, 2009, 40(2):87-100, 
Horner-Johnson—LM, PSRH 52:1—3,572 text, 247 abstract

http://dx.doi.org/10.1111/j.1728-4465.2009.00192.x.

16. Mumford SL et al., Pregnancy intentions - a complex construct and call for new measures, Fertility and Sterility, 2016, 106(6):1453-1462, http://dx.doi.org/10.1016/ j.fertnstert.2016.07.1067.

17. Finer LB and Zolna MR, Declines in unintended pregnancy in the United States, 2008-2011, New England Journal of Medicine, 2016, 374(9):843-852, http://dx.doi.org/ 10.1056/NEJMsa1506575.

18. Guttmacher Institute, Unintended pregnancy in the United States, Fact Sheet, New York: Guttmacher Institute, 2019, https://www.guttmacher.org/fact-sheet/ unintended-pregnancy-united-states.

19. Mosher WD, Jones J and Abma JC, Intended and unintended births in the United States: 1982-2010, National Health Statistics Reports, 2012, No. 55.

20. Dott $\mathrm{M}$ et al., Association between pregnancy intention and reproductive-health related behaviors before and after pregnancy recognition, National Birth Defects Prevention Study, 1997-2002, Maternal and Child Health Journal, 2010, 14(3):373-381, http://dx.doi.org/10.1007/s10995-009-0458-1.

21. Kost $\mathrm{K}$ and Lindberg L, Pregnancy intentions, maternal behaviors and infant health: investigating relationships with new measures and propensity score analysis, Demography, 2015, 52(1):83-111, http://dx.doi.org/10.1007/s13524-014-0359-9.

22. Lindberg L et al., Pregnancy intentions and maternal and child health: an analysis of longitudinal data in Oklahoma, Maternal and Child Health Journal, 2015, 19(5):10871096, http://dx.doi.org/10.1007/s10995-014-1609-6.

23. Mohllajee AP et al., Pregnancy intention and its relationship to birth and maternal outcomes, Obstetrics \& Gynecology, 2007, 109(3):678-686, http://dx.doi.org/10.1097/ 
Horner-Johnson—LM, PSRH 52:1—3,572 text, 247 abstract

01.AOG.0000255666.78427.c5.

24. Kavanaugh ML et al., Parents' experience of unintended childbearing: a qualitative study of factors that mitigate or exacerbate effects, Social Science E Medicine, 2017, 174:133-141, http://dx.doi.org/10.1016/ j.socscimed.2016.12.024.

25. Reichard A et al., Diagnosis isn't enough: understanding the connections between high health care utilization, chronic conditions and disabilities among U.S. working age adults, Disability and Health Journal, 2015, 8(4):535-546, http://dx.doi.org/10.1016/j.dhjo.2015.04.006.

26. Tarasoff LA et al., Maternal disability and risk for pregnancy, delivery and postpartum complications: a systematic review and meta-analysis, American Journal of $\begin{array}{llll}\text { Obstetrics } & \mathcal{E} \quad \text { Gynecology, 222(1):27.e1-27.e32, }\end{array}$ http://dx.doi.org/10.1016/j.ajog.2019.07.015.

27. Mitra M et al., Maternal characteristics, pregnancy complications and adverse birth outcomes among women with disabilities, Medical Care, 2015, 53(12):1027-1032, http://dx.doi.org/10.1097/MLR.0000000000000427.

28. Centers for Disease Control and Prevention (CDC), National Survey of Family Growth, 2019, https://www.cdc.gov/nchs/nsfg/index.htm.

29. CDC, 2013-2015 National Survey of Family Growth (NSFG): Summary of Design and Data Collection Methods, no date, https://www.cdc.gov/nchs/data/nsfg/NSFG_20132015_Summary_Design_Data_Collection.pdf.

30. Dorsey R and Graham G, New HHS data standards for race, ethnicity, sex, primary language and disability status, JAMA, 2011, 306(21):2378-2379, http://dx.doi.org/10.1001/jama. 2011.1789.

31. Archer KJ and Lemeshow S, Goodness-of-fit test for a logistic regression model 
Horner-Johnson—LM, PSRH 52:1—3,572 text, 247 abstract

fitted using survey sample data, Stata Journal, 2006, 6(1):97-105, http://dx.doi.org/ 10.1177/1536867X0600600106.

32. King G, Tomz M and Wittenberg J, Making the most of statistical analyses: improving interpretation and presentation, American Journal of Political Science, 2000, 44(2):347-361, http://dx.doi.org/10.2307/2669316.

33. Heiman E, Haynes S and McKee M, Sexual health behaviors of deaf American Sign Language (ASL) users, Disability and Health Journal, 2015, 8(4):579-585, http://dx.doi.org/10.1016/j.dhjo.2015.06.005.

34. Zodda JJ, Condom use among deaf college students, Journal of the American Deafness and Rehabilitation Association, 2015, 49(2):86-100, https://repository.wcsu.edu/jadara/vol49/iss2/4.

35. McKee MM et al., Impact of communication on preventive services among deaf American Sign Language users, American Journal of Preventive Medicine, 2011, 41(1):7579, http://dx.doi.org/10.1016/j.amepre.2011.03.004.

36. Heuttel KL and Rothstein WG, HIV/AIDS knowledge and information sources among deaf and hearing college students, American Annals of the Deaf, 2001, 146(3):280-286, http://dx.doi.org/10.1353/aad.2012.0067.

37. Bat-Chava Y, Martin D and Kosciw JG, Barriers to HIV/AIDS knowledge and prevention among deaf and hard of hearing people, AIDS Care, 2005, 17(5):623-634, http://dx.doi.org/10.1080/09540120412331291751.

38. Lagu $\mathrm{T}$ et al., Access to subspecialty care for patients with mobility impairment: a survey, Annals of Internal Medicine, 2013, 158(6):441-446, http://dx.doi.org/10.7326/ 0003-4819-158-6-201303190-00003.

39. Mitra $\mathrm{M}$ et al., Access to and satisfaction with prenatal care among pregnant 
Horner-Johnson—LM, PSRH 52:1—3,572 text, 247 abstract

women with physical disabilities: findings from a national survey, Journal of Women's Health, 2017, 26(12):1356-1363, http://dx.doi.org/10.1089/jwh.2016.6297.

40. Aunos $\mathrm{M}$ and Feldman MA, Attitudes towards sexuality, sterilization and parenting rights of persons with intellectual disabilities, Journal of Applied Research in Intellectual Disabilities, 2002, 15(4):285-296, http://dx.doi.org/10.1046/j.1468-3148.2002. 00135.x.

41. $\mathrm{Wu} \mathrm{J}$ et al., Looking back while moving forward: a justice-based, intersectional approach to research on contraception and disability, Contraception, 2019, 99(5):267271, http://dx.doi.org/10.1016/j.contraception.2019.01.006.

42. McCabe MP, Sexual knowledge, experience and feelings among people with disability, Sexuality and Disability, 1999, 17(2):157-170, http://dx.doi.org/10.1023/ A:1021476418440.

43. McCarthy M, Contraception and women with intellectual disabilities, Journal of Applied Research in Intellectual Disabilities, 2009, 22(4):363-369, http://dx.doi.org/ 10.1111/j.1468-3148.2008.00464.x.

44. Guastaferro K, Benka-Coker ML and Lutzker JR, A story of mothers with intellectual and developmental disabilities, in: Lutzker JR, Guastaferro K and BenkaCoker ML, eds., Maltreatment of People with Intellectual and Developmental Disabilities, Washington, DC: American Association on Intellectual and Developmental Disabilities, 2016, pp. 187-206.

45. Mann DR and Honeycutt T, Understanding the disability dynamics of youth: health condition and limitation changes for youth and their influence on longitudinal survey attrition, Demography, 2016, 53(3):749-776, http://dx.doi.org/10.1007/s13524016-0469-7. 
Horner-Johnson—LM, PSRH 52:1—3,572 text, 247 abstract

46. Ward B et al., Disability items from the Current Population Survey (2008-2015) and permanent versus temporary disability status, American Journal of Public Health, 2017, 107(5):706-708, http://dx.doi.org/10.2105/AJPH.2017.303666. 


\begin{abstract}
Authors' affiliations
Willi Horner-Johnson is associate professor, Institute on Development and Disability; Mekhala Dissanayake is research programmer, Department of Obstetrics and Gynecology; Aaron B. Caughey is professor and chair, Department of Obstetrics and Gynecology; and Blair G. Darney is assistant professor, Department of Obstetrics and Gynecology-all at the Oregon Health \& Science University, Portland. Justine $P$. Wu is assistant professor, Department of Family Medicine, University of Michigan Medical School, Ann Arbor.
\end{abstract}

\title{
Acknowledgments
}

This research was supported in part by award R21HD081309 from the Eunice Kennedy Shriver National Institute of Child Health and Human Development of the National Institutes of Health, and by grant 0118WH from the Department of Pediatrics, Oregon Health \& Science University. Additional support was provided by grant K12HS022981 from the Agency for Healthcare Research and Quality and the Institute on Development and Disability at Oregon Health $\mathcal{E}$ Science University. The content is solely the responsibility of the authors and does not necessarily represent the official views of the National Institutes of Health or the other funders. The funding agencies had no role in conducting the research or preparing the manuscript for submission.

Author contact: hornerjo@ohsu.edu 
TABLE 1. Percentage distribution of women reporting pregnancies in the previous five years, by $s$ demographic characteristics, National Survey of Family Growth, 2011-2015

\begin{tabular}{|c|c|c|c|c|c|c|}
\hline \multirow[t]{2}{*}{ Characteristic } & \multicolumn{2}{|c|}{ Disability status } & \multicolumn{4}{|c|}{ Disability type } \\
\hline & $\begin{array}{l}\text { No } \\
\text { disability } \\
(\mathrm{N}=2,344)\end{array}$ & $\begin{array}{l}\text { Any } \\
\text { disability } \\
(\mathrm{N}=745)\end{array}$ & $\begin{array}{l}\text { Hearing } \\
(\mathrm{N}=96)\end{array}$ & $\begin{array}{l}\text { Vision } \\
(\mathrm{N}=201)\end{array}$ & $\begin{array}{l}\text { Cognitive } \\
(\mathrm{N}=489)\end{array}$ & $\begin{array}{l}\text { Phys } \\
(\mathrm{N}=1\end{array}$ \\
\hline Disability status/type & 83.6 & 16.4 & 2.8 & 4.9 & 11.5 & \\
\hline Age & & $* * *$ & & * & $* * *$ & \\
\hline $15-24$ & 18.9 & 29.9 & 25.8 & 31.5 & 32.1 & 13 \\
\hline $25-34$ & 53.0 & 49.0 & 48.8 & 46.9 & 47.2 & 5 \\
\hline $35-44$ & 28.1 & 21.0 & 25.5 & 21.6 & 20.7 & 32 \\
\hline Race/ethnicity & & * & & $* * *$ & & \\
\hline White & 54.1 & 55.9 & 64.1 & 44.1 & 58.0 & 56 \\
\hline Black & 14.3 & 17.3 & 15.6 & 27.7 & 12.5 & 17 \\
\hline Hispanic & 23.3 & 22.7 & 16.8 & 24.8 & 24.1 & 21 \\
\hline Other & 8.2 & 4.1 & 3.6 & 3.5 & 5.4 & \\
\hline Partner statust & & $* * *$ & & ** & $* * *$ & $* * *$ \\
\hline Married/cohabiting & 76.5 & 59.7 & 70.2 & 64.3 & 56.5 & 5 \\
\hline Single/divorced/other & 23.5 & 40.3 & 29.8 & 35.7 & 43.5 & 40 \\
\hline Education & & $* * *$ & * & $* * *$ & $* * *$ & ** \\
\hline zcollege degreeł & 41.8 & 18.5 & 26.9 & 16.4 & 15.5 & 20. \\
\hline <college degree & 58.2 & 81.5 & 73.1 & 83.6 & 84.5 & 79 \\
\hline $\begin{array}{l}\text { Income (as } \% \text { of } \\
\text { federal poverty level) }\end{array}$ & & $* * *$ & * & $* * *$ & $* * *$ & $* * *$ \\
\hline$<100$ & 30.1 & 47.0 & 40.7 & 51.5 & 49.7 & $4 \mathrm{c}$ \\
\hline $100-249$ & 30.5 & 31.7 & 40.2 & 28.3 & 29.9 & \\
\hline$\geq 250$ & 39.4 & 21.4 & 19.1 & 20.2 & 20.4 & 14. \\
\hline
\end{tabular}




\begin{tabular}{|c|c|c|c|c|c|c|}
\hline Parity & & $* * *$ & $* *$ & * & $* *$ & \\
\hline 0 & 8.5 & 13.3 & 19.0 & 13.1 & 13.7 & \\
\hline 1 & 34.2 & 31.9 & 33.9 & 35.3 & 31.1 & \\
\hline$\geq 2$ & 57.3 & 54.8 & 47.1 & 51.6 & 55.2 & \\
\hline Total & 100.0 & 100.0 & 100.0 & 100.0 & 100.0 & \\
\hline \multicolumn{7}{|c|}{$\begin{array}{l}\text { *Significantly different from no disability at } \mathrm{p}<.05 .{ }^{*} \text { Significantly different from no disability at } \mathrm{f} \\
\text { different from no disability at } \mathrm{p}<.001 .+ \text { At time of interview; partner status at conception may ha } \\
\text { pregnancy. } \ddagger \text { Includes associate's, bachelor's, master's, doctoral or professional degree. Notes: Cat } \\
\text { mutually exclusive; women could have more than one type of disability. Sample sizes are unwei } \\
\text { percentages are weighted to represent the U.S. population of reproductive-age women. Percenta } \\
\text { because of rounding. }\end{array}$} \\
\hline
\end{tabular}


FIGURE 1. Proportion of pregnancies that were unintended (mistimed or unwanted), by women's disability status and type of disability

$\%$

100

80

60

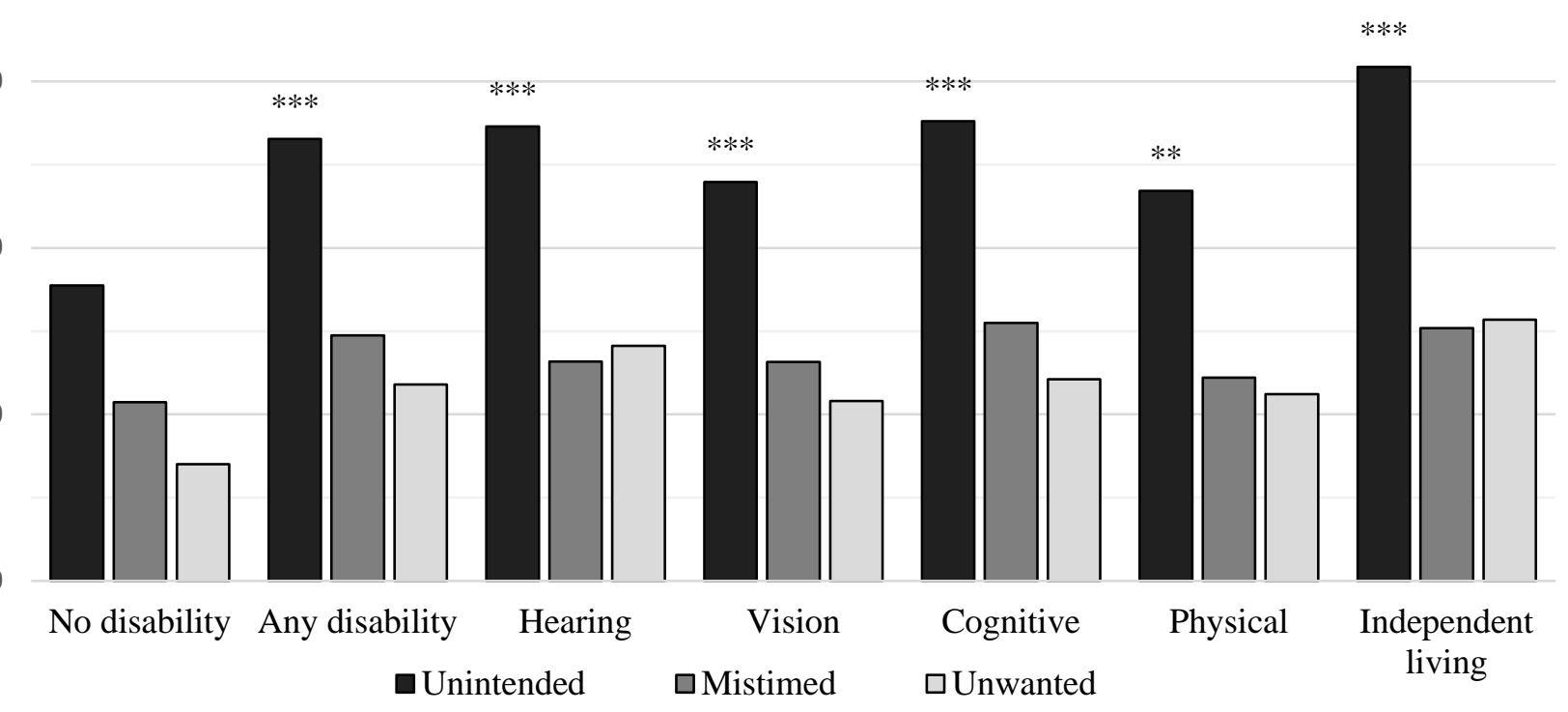

**Significantly different from no disability at $\mathrm{p}<.01 .{ }^{* * *}$ Significantly different from no disability at $\mathrm{p}<.001$.

Notes: Percentages are weighted. Unweighted total number of pregnancies $=5,861$. 
FIGURE 2. Adjusted odds ratios (and 95\% confidence intervals) from logistic regression analyses examining associations between disability type and pregnancy unintendedness

This article is protected by copyright. All rights reserved. 


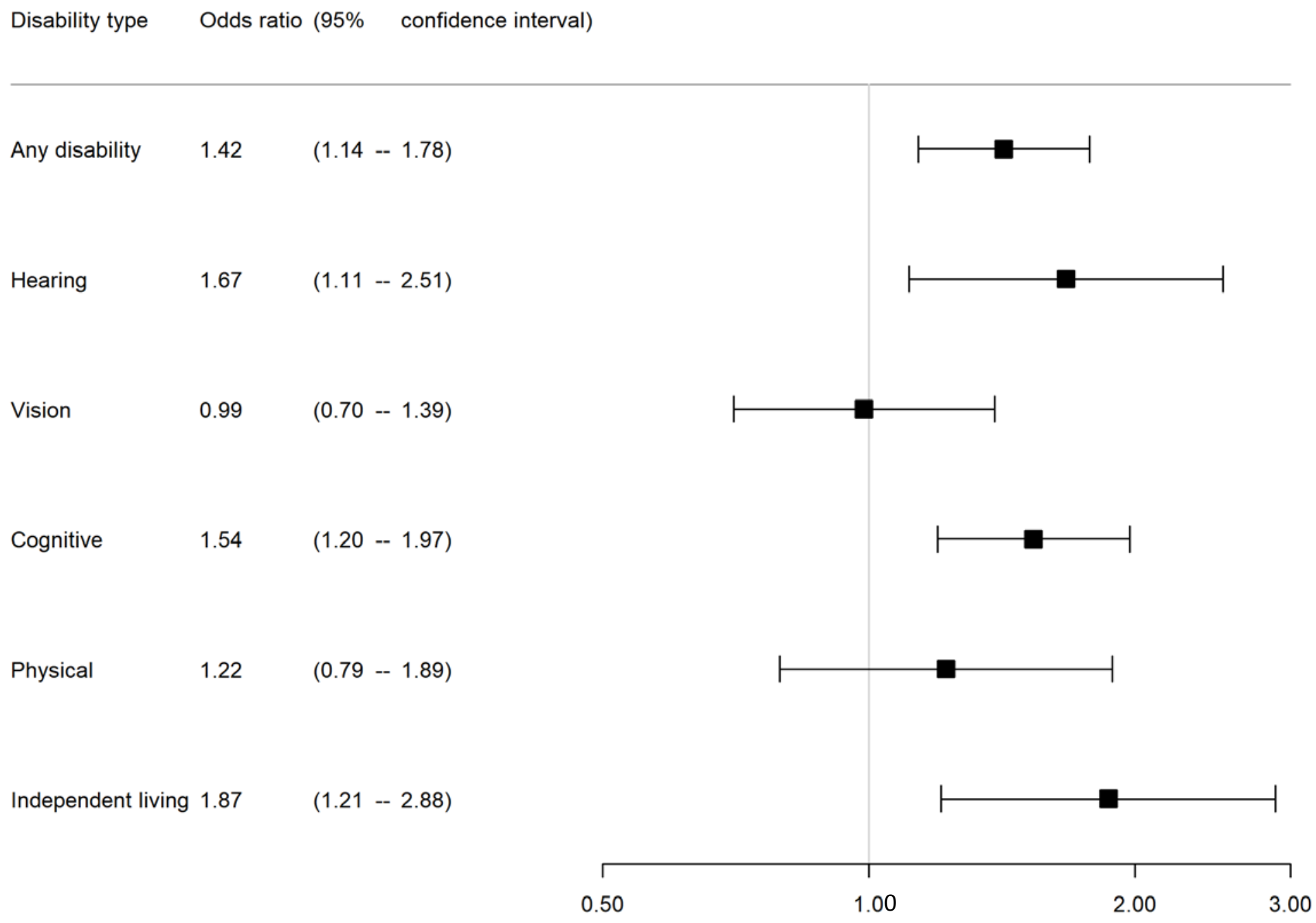

Note: Adjusted for age, race and ethnicity, partner status, education, income and parity.

This article is protected by copyright. All rights reserved. 
TABLE 1. Percentage distribution of women reporting pregnancies in the previous five years, by selected social and demographic characteristics, National Survey of Family Growth, 2011-2015

\begin{tabular}{|c|c|c|c|c|c|c|c|}
\hline \multirow[t]{2}{*}{ Characteristic } & \multicolumn{2}{|c|}{ Disability status } & \multicolumn{5}{|c|}{ Disability type } \\
\hline & $\begin{array}{l}\text { No } \\
\text { disability } \\
(\mathrm{N}=2,344)\end{array}$ & $\begin{array}{l}\text { Any } \\
\text { disability } \\
(\mathrm{N}=745)\end{array}$ & $\begin{array}{l}\text { Hearing } \\
(\mathrm{N}=96)\end{array}$ & $\begin{array}{l}\text { Vision } \\
(\mathrm{N}=201)\end{array}$ & $\begin{array}{l}\text { Cognitive } \\
(\mathrm{N}=489)\end{array}$ & $\begin{array}{l}\text { Physical } \\
(\mathrm{N}=129)\end{array}$ & $\begin{array}{l}\text { Independent } \\
\text { living } \\
(\mathrm{N}=144)\end{array}$ \\
\hline Disability status/type & 83.6 & 16.4 & 2.8 & 4.9 & 11.5 & 3.0 & 3.0 \\
\hline Age & & $* * *$ & & * & $* * *$ & & * \\
\hline $15-24$ & 18.9 & 29.9 & 25.8 & 31.5 & 32.1 & 13.5 & 31.9 \\
\hline $25-34$ & 53.0 & 49.0 & 48.8 & 46.9 & 47.2 & 54.5 & 44.0 \\
\hline $35-44$ & 28.1 & 21.0 & 25.5 & 21.6 & 20.7 & 32.0 & 24.1 \\
\hline Race/ethnicity & & * & & $* * *$ & & & \\
\hline White & 54.1 & 55.9 & 64.1 & 44.1 & 58.0 & 56.1 & 57.2 \\
\hline Black & 14.3 & 17.3 & 15.6 & 27.7 & 12.5 & 17.3 & 19.4 \\
\hline Hispanic & 23.3 & 22.7 & 16.8 & 24.8 & 24.1 & 21.8 & 19.0 \\
\hline Other & 8.2 & 4.1 & 3.6 & 3.5 & 5.4 & 4.8 & 4.4 \\
\hline Partner statust & & $* * *$ & & $* *$ & $* * *$ & $* * *$ & $* * *$ \\
\hline Married/cohabiting & 76.5 & 59.7 & 70.2 & 64.3 & 56.5 & 59.2 & 44.9 \\
\hline Single/divorced/other & 23.5 & 40.3 & 29.8 & 35.7 & 43.5 & 40.8 & 55.1 \\
\hline Education & & $* * *$ & * & $* * *$ & $* * *$ & $* *$ & $* * *$ \\
\hline zcollege degreef & 41.8 & 18.5 & 26.9 & 16.4 & 15.5 & 20.3 & 10.4 \\
\hline <college degree & 58.2 & 81.5 & 73.1 & 83.6 & 84.5 & 79.7 & 89.6 \\
\hline
\end{tabular}




\begin{tabular}{l} 
Income (as \% of \\
federal poverty level) \\
$<100$ \\
$100-249$ \\
$\geq 250$ \\
\\
Parity \\
0 \\
1 \\
$\geq 2$ \\
\\
Total \\
\hline
\end{tabular}

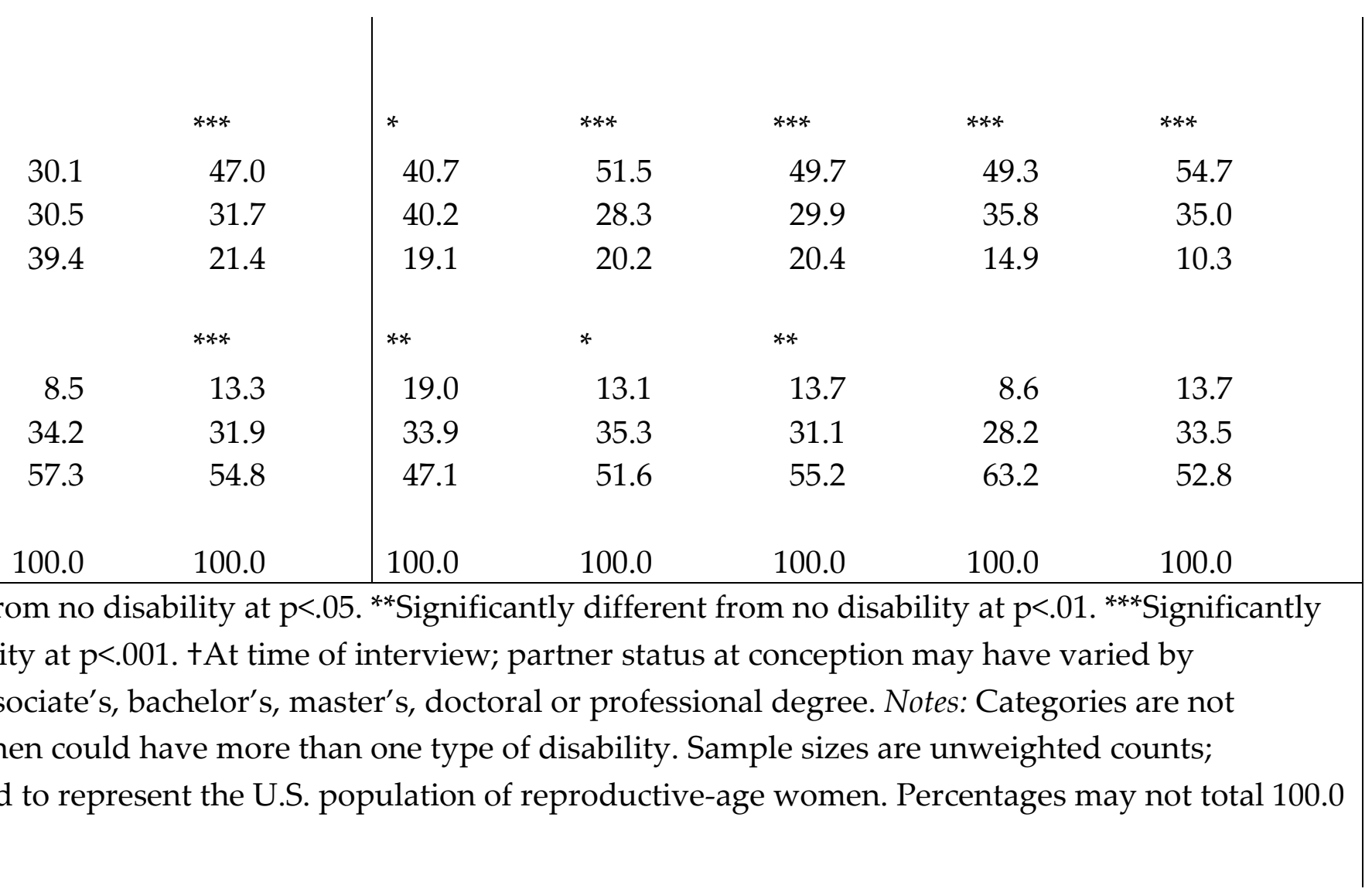

